\title{
Clinico-epidemiological profile of thalassemia patients in a tertiary care center
}

\author{
Singh M. ${ }^{1}$, Dayal R. ${ }^{2}$, Kumar N. ${ }^{3}$, Singh S.P. ${ }^{4}$, Gupta L.K. ${ }^{5}$, Nayak M. ${ }^{6}$, Sharma R.K. ${ }^{7}$, Yadav A. ${ }^{8}$ \\ ${ }^{1}$ Dr. Madhu Singh, Lecturer, Department of Paediatrics, ${ }^{2}$ Prof (Dr). R. Dayal, Professor and Head, Department of \\ Paediatrics, ${ }^{3}$ Prof (Dr). Neeraj Kumar, Professor, Department of Paediatrics, ${ }^{4}$ Dr. Sheo Pratap Singh, Assistant Professor, \\ ${ }^{5}$ Dr. L.K. Gupta, Associate Professor, Government Medical College, Firozabad ${ }^{6}$ Dr. Madhu Nayak, Assistant Professor, \\ ${ }^{7}$ Dr. Ram Kshitij Sharma, Lecturer, ${ }^{8}$ Dr. Akriti Yadav, Junior Resident; ${ }^{1,2,3,4,6,7,8}$ authors are attached with Department of \\ Pediatrics, S.N. Medical College, Agra, UP, India.
}

Corresponding Author: Dr. L. K. Gupta, Associate Professor, Department of Pediatrics, Government Medical College, Firozabad (U.P.) India. E-mail: guptaneeta98@gmail.com

\begin{abstract}
Introduction: Thalassemias are inherited blood disorders characterized by abnormal hemoglobin production. There are two main types, alpha thalassemia, and beta-thalassemia. Beta Thalassemia Major (also called Cooley's Anemia) is a serious illness. Symptoms appear in the first two years of life and include paleness of the skin, poor appetite, irritability, and failure to grow. There is absent or decreased production of normal hemoglobin, resulting in microcytic anemia of varying degrees. The thalassemias have a distribution concomitant with areas where P. falciparum malaria is common. The alpha thalassemias are concentrated in Southeast Asia, Malaysia, and southern China. The beta thalassemias are seen primarily in the areas surrounding the Mediterranean Sea, Africa, and Southeast Asia. Proper treatment includes routine blood transfusions and other therapies which can lead to iron overload and contraction of infections such as HIV, HCV, and HBV shortening the life span of patients. On the other hand, inadequate transfusions may lead to severe anemia and debility. Material and Methods: This retrospective record-based cross-sectional study was conducted in S.N. Medical College, Agra. Results: In our tertiary center, we have 103 registered patients of thalassemia, in which 44 are females and 59 are males. Out of the 103 thalassemia cases, 95 (92.2\%) belonged to beta-thalassemia major, 4(3.8\%) of betathalassemia intermediate, and $1(0.9 \%)$ of beta-thalassemia minor category. Fever was the most common presenting symptom. Pallor and hepatomegaly were the most common signs among cases. Conclusion: Hemoglobinopathies are the commonest hereditary disorders in India and pose a major health problem. The data on the prevalence of $\beta$-thalassemias and other hemoglobinopathies in different caste/ethnic groups of India is scarce.
\end{abstract}

Keywords: Hemoglobinopathies, $\beta$-thalassemia, Iron Chelating Agents

\section{Introduction}

Thalassemia is the most common genetic blood disease in the world and varies in different population group in the world. World Health Organization (WHO) estimates that at least $6.5 \%$ of the world populations are carries of different inherited disorders of hemoglobin.

Thalassemia syndromes are caused by inherited mutations that decrease the synthesis of either alpha or beta globin chains of hemoglobin. Imbalance in globin chain synthesis results in anemia, tissue hypoxia, and red cell hemolysis.

Manuscript received: $28^{\text {th }}$ August 2019 Reviewed: $8^{\text {th }}$ September 2019

Author Corrected: $14^{\text {th }}$ September 2019

Accepted for Publication: 17 $7^{\text {th }}$ September 2019
In the normal adult, hemoglobin A, which is composed of two alpha and two beta globins $\left(\alpha^{2} \beta^{2}\right)$, is the most prevalent, comprising about $95 \%$ of all hemoglobin. Two minor hemoglobins also occur: hemoglobin $\mathrm{A}_{2}$, composed of two alpha and two delta globins $\left(\alpha^{2} \delta^{2}\right)$ which comprises $2-3.5 \%$ of hemoglobin, while hemoglobin F, composed of two alpha and two gamma globins $\left(\alpha^{2} \gamma^{2}\right)$ which comprises less than $2 \%$ of hemoglobin. Hemoglobin F, or fetal hemoglobin, is produced by the fetus in utero and until about 48 weeks after birth. Hemoglobin $\mathrm{F}$ has a high oxygen-affinity to attract oxygen from maternal blood and deliver it to the fetus. After birth, the production of adult hemoglobin rapidly increases and fetal hemoglobin production drops 


\section{Original Research Article}

off. The genes controlling globin production are on chromosome 16 (alpha-globin genes: " $\alpha ")$, and chromosome 11 (beta: " $\beta$ ", gamma: " $\gamma$ ", and delta: " $\delta$ " genes). Their clinical severity widely varies, ranging from asymptomatic forms to severe or even fatal entities. Individuals with beta-thalassemia major or homozygous type manifest with severe transfusiondependent anemia. Those with beta-thalassemia minor or hetero-zygous genotype present with mild asymptomatic anemia. The heterogeneous variant of moderate severity is called beta-thalassemia intermedia [1]. The patients suffering from beta-thalassemia major and $\mathrm{Hb} \mathrm{E} / \mathrm{beta}$-thalassemia do not survive for more than 5 years without blood transfusion [2].

In India, it is the most common single-gene disorder [3]. Every year one-tenth of the world's thalassemic population are born in India [4]. The carrier rate for beta-thalassemia gene ranges from $1 \%$ to $3 \%$ in southern and 3\% to $15 \%$ in northern parts of India [5-7]. Thalassemia affects physical growth and delays maturation. Its management also imposes a huge economic burden on the families of the affected [8].

Experiences from other endemic countries in Europe have shown that public education followed by screening and genetic counseling can substantially reduce the incidence of thalassemia [9-10].Hospital-based registers give a good approximation of the disease pattern in the community when there is unavailability of formal population-based screening of hemoglobino-pathies. With this background, this study was done in Agra city. The objectives of this study were to assess the pattern, clinical presentations, complications, and management practices among thalassemia cases.

\section{Material and Methods}

Type of study: This retrospective record-based crosssectional study was conducted in S.N. Medical College, Agra. The secondary data of all confirmed cases of thalassemia were examined by the investigators.

Sampling methods and sample size: The information regarding sociodemographic details of the patients, type of thalassemia, risk factors such as the family history of genetic disorders, history of consanguinity among parents, symptoms, signs, and complications associated with thalassemia, hematological reports, and management practices was recorded in a predesigned validated proforma.

Data collection procedure: This retrospective study involved patients who were admitted in the Thalassemia Ward, Department of Pediatrics, S.N. Medical College, Agra for the purpose of blood transfusion and for getting oral iron chelating agents. Ethical clearance was taken from ethical society. Parents or guardians were informed about the purpose of the study. For each patient a detailed history was taken from mother or the attendant. After taking brief history preliminary selection was done, and the purpose to the study was explained in details to its subject. After taking consent from the parents, data was collected, which included sex, age at presentation, age at diagnosis and clinical symptoms at presentation. A thorough physical examination was done in each patient.

\section{Results}

Out of the 103 thalassemia cases, $95(92.2 \%)$ belonged to beta-thalassemia major, 4(3.8\%) of beta-thalassemia intermediate, and $1(0.9 \%)$ of beta-thalassemia minor category.

Table-1: Epidemiological profile of thalassemia patients

\begin{tabular}{|c|c|c|}
\hline & & $\mathbf{N}(\%)$ \\
\hline \multirow[t]{6}{*}{ Age group(yrs) } & $<1$ & 17 \\
\hline & $1.1-5$ & 37 \\
\hline & $5.5-10$ & 23 \\
\hline & $10.1-15$ & 18 \\
\hline & $15.1-20$ & 6 \\
\hline & $>20$ & 2 \\
\hline \multirow[t]{2}{*}{ Gender } & Male & 59 \\
\hline & Female & 44 \\
\hline \multirow[t]{2}{*}{ Socioeconomic status } & Above the poverty line & 70 \\
\hline & Below poverty line & 33 \\
\hline \multirow[t]{2}{*}{ Residence } & Urban & 90 \\
\hline & Rural & 13 \\
\hline
\end{tabular}

Pediatric Review: International Journal of Pediatric Research Available online at: www.medresearch.in 485|P a g e 


\section{Original Research Article}

The mean age of cases was 6.8 years. The age at diagnosis ranged from 0.1 to 11 years. The majority of cases were under-fives $57(55.3 \%)$ and were male. The family history of thalassemia was positive among 5(4.8\%) cases. History of consanguineous marriage was positive among $3(2.9 \%)$ cases, 2 involving marriages between second-degree relatives and one involving third-degree relatives [Table 1].

Table-2: Clinical profile of thalassemia patients

\begin{tabular}{|l|l|c|}
\hline Clinical features & & N (\%) \\
\hline \multirow{5}{*}{ Symptoms } & Fever & $19(18.6 \%)$ \\
\cline { 2 - 3 } & Abdominal distension & $4(4.4 \%)$ \\
\cline { 2 - 3 } & Breathlessness & $4(4.4 \%)$ \\
\cline { 2 - 3 } & Diarrhea & $4(4.4 \%)$ \\
\cline { 2 - 3 } & Headache & $2(2 \%)$ \\
\cline { 2 - 3 } & Dizziness & $5(4.8 \%)$ \\
\hline \multirow{5}{*}{ Signs } & Pallor & $99(97.8 \%)$ \\
\cline { 2 - 3 } & Hepatomegaly & $96(94 \%)$ \\
\cline { 2 - 3 } & Splenomegaly & $85(82.5 \%)$ \\
\cline { 2 - 3 } & Jaundice & $10(9.7 \%)$ \\
\hline \multirow{5}{*}{ Bone deformities } & Bossing of skull & $15(75 \%)$ \\
\cline { 2 - 3 } & Hypertrophy of maxilla & $8(40 \%)$ \\
\cline { 2 - 3 } & Prominent malar eminence & $5(25 \%)$ \\
\cline { 2 - 3 } & Depression of the nasal bridge & $4(20 \%)$ \\
\hline
\end{tabular}

Fever was the most common presenting symptom 19 (18.6\%). Pallor 99 (97.8\%) followed by hepatomegaly 96 (94\%) were the most common signs among cases. Bone deformities were reported in $20(19.1 \%)$ cases, all of which were betathalassemia major cases [Table 2].

Data on weight for age were available only among 46 out of 57 under-fives. 18 (39.1\%) out of 46 under-fives were underweight. Data on height for age were available only among 21 out of 57 under-five patients. The proportion of under-fives with stunting was $11(52.4 \%)$. The anthropometric indices of thalassemia cases did not vary significantly with gender. Among those aged above 20 years, anthropometric data were available in 2 cases. It comprised of an underweight male and a male of normal weight.

Blood transfusion was given to all cases except for the lone case of beta-thalassemia minor. Iron chelation therapy using deferasirox was given in $51(27.9 \%)$ cases. It was given to $70(73.6 \%)$ out of 95 cases with beta-thalassemia major. Among cases $(n=70)$ in whom deferasirox was given, mean serum ferritin values at the start of therapy were $2500 \mathrm{pmol} / \mathrm{L}$. Other medications such as folic acid were given to $52(50.8 \%)$ cases. The complication in the form of hemosiderosis as a result of repeated blood transfusion was reported in one case.

\section{Discussion}

The proportion of cases diagnosed within the first 6 months in this study was much lesser than the proportion ranging from $46.7 \%$ to $60.7 \%$ in other parts of India [8, 11-12]. Hence, awareness of this condition needs further improvement in this setting. Fever was the most common symptom among cases probably due to associated infections. Pallor was the most common sign in this study similar to the findings of other studies [1314]. Hypertrophy of maxilla was present in 8 cases, all of which were beta-thalassemia major cases. Their mean age of starting blood transfusion was 7. This emphasizes the need for routine dental care in all thalassemia patients, along with the initiation of blood transfusions from an early age to prevent maxillary deformities, per standard guidelines [15].

In this study, $39.1 \%$ of patients were underweight compared to $23.6 \%$ [16] and $45.7 \%$ [17] reported in other studies. The proportion of cases with stunting in the Iranian study was $65.7 \%$ which was more than our 


\section{Original Research Article}

observations. Failure to thrive results from feeding problems, irritability, and intercurrent infections. Hence, nutritional care is very important in the management of thalassemia. The mean number of blood transfusions in a Sri Lankan study was 10.4 in the past year which was similar to our observations [18]. In the study done at Ahmedabad, India, the frequency of transfusion was once or more in a month among $25.6 \%$ cases which were also similar to our findings [19].

This was per guidelines where the usual frequency of one transfusion every 2-4 weeks is recommended among thalassemia cases so that hemoglobin level is maintained more than 9-10.5 g/dl [20]. This blood transfusion regimen promotes proper growth and prevents bone marrow expansion and iron overload among most patients. The posttransfusion hemoglobin also should not be $>14-15 \mathrm{~g} / \mathrm{dl}$, as it can lead to a greater risk of hyperviscosity and stroke [21]. In this study, the mean posttransfusion level of hemoglobin was $10 \mathrm{~g} / \mathrm{dl}$ indicating appropriate transfusion practices as per guidelines. Furthermore, transfusion in severe thalassemia genotypes as per the guidelines usually starts within the first 2 years of life. Folic acid deficiency has been reported in thalassemia major and intermedia because of increased erythropoiesis.

Daily oral supplementation with $1 \mathrm{mg}$ of folic acid is recommended for persons with low hemoglobin levels. Supplementation also reduces the risk of thrombosis. Therefore, in this study too, folic acid was given in more than half of the cases.

\section{Conclusion}

We evaluated all the patients registered to us under thalassemia unit. Blood transfusions along with oral iron chelating agents were provided free of cost to the patients. Most of our cases belonged to a severe variety of beta-thalassemia requiring multiple blood transfusions. S. Iron and S. Ferritin was serially monitored in patients requiring frequent blood transfusions. Oral iron chelating agents (Tab Deferasirox) is being provided to prevent complications associated with iron overload.

Among the under-fives, more than one-third were underweight and more than half were stunted. Hence, good nutritional care along with calcium and Vitamin D supplement needs to be given among the diseased to prevent growth impairment. Hypertrophy of maxilla was seen in a few cases, and their mean age of starting blood transfusion was 7 years. This emphasizes the need for routine dental care in all thalassemia patients and initiation of blood transfusions within 2 years of age in severe thalassemia.

Since most patients are suffering with severe thalassemia, awareness of this condition is must in our setting to improve carrier identification, genetic counseling, and prenatal diagnosis among high-risk groups carrying thalassemia traits for minimizing its incidence.

\section{What the study adds to the existing knowledge?}

In the present study 103 thalassemia patients were admitted in the institute. Since, majority of them were diagnosed with severe thalassemia, awareness of this condition was pivotal to improve carrier identification, genetic counseling, and prenatal diagnosis among highrisk groups carrying thalassemia traits for minimizing its incidence.

Funding: Nil, Conflict of interest: None initiated, Permission from IRB: Yes

\section{References}

1. Kumar V, Abbasi AK, Aster JC. Red blood cells and bleeding disorders. In: Robbins and Cotran, Pathologic basis of Disease. $9^{\text {th }}$ ed. Gurgaon: Reed Elsevier India Private Limited; 2015.p.638,639,641.

2. Shekhar HU, Kabir Y, Hossain MM, Mesbah-Uddin M, Khatun-EJannat K, Hossain MS, et al. Blood transfusion mediated viral infections in thalassemic children in Bangladesh. J Med Sci. 2007;7(1):131-135. doi: $10.3923 /$ jms.2007.131.135

3. Lokeshwar MR. Late Hony. Surg. Cmde. Dr. Shantilal C. Sheth oration presentation during PEDICON 2006, Delhi, January 6th, 2006. Progress in the management of thalassemia. Indian Pediatr. 2006;43 (6): 503-506.

4. Bashyam MD1, Bashyam L, Savithri GR, Gopikrishna M, Sangal V, Devi AR. Molecular genetic analyses of beta-thalassemia in South India reveals rare mutations in the beta-globin gene. J Hum Genet. 2004; 49(8):408-413. Epub 2004 Jul 24. doi: 10.1007/s10038004-0169-9

5. Balgir RS. Spectrum of hemoglobinopathies in the state of Orissa, India: a ten years cohort study. J Assoc Physicians India. 2005;53:1021-1026. 


\section{Original Research Article}

6. Manglani M1, Lokeshwar MR, Vani VG, Bhatia N, Mhaskar V. 'NESTROFT'--an effective screening test for beta thalassemia trait. Indian Pediatr. 1997;34(8): 702-707.

7. Varawalla NY, Old JM, Sarkar R, Venkatesan R, Weatherall DJ. The spectrum of beta-thalassaemia mutations on the Indian subcontinent: the basis for prenatal diagnosis. Br J Haematol. 1991;78(2):242-247. doi: 10.1111/j.1365-2141.1991.tb04423.x

8. Thavorncharoensap M1, Torcharus K, Nuchprayoon I, Riewpaiboon A, Indaratna K, Ubol BO. Factors affecting health-related quality of life in Thai children with thalassemia. BMC Blood Disord. 2010;10:1. doi: 10.1186/1471-2326-10-1.

9. Angastiniotis M, Modell B, Englezos P, Boulyjenkov V. Prevention and control of haemoglobinopathies. Bull World Health Organ. 1995;73(3):375-386.

10. Angastiniotis M, Kyriakidou S, Hadjiminas MG. How thalassemia was controlled in Cyprus. World Health Forum. 1986;7(3):291-297.

11. Taneja R, Malik P, Sharma M, Agarwal MC. Multiple transfused thalassemia major: ocular manifestations in a hospital-based population. Indian $\mathrm{J}$ Ophthalmol. 2010; 58(2):125-130. doi: 10.4103/03014738. 60083 .

12. Shanthi G, Balasubramanyam D, Srinivasan R. Clinical and Demographical Studies of Beta ()Thalassemia in Tamil Nadu. Res J Pharm Biol Chem Sci. 2013;4 (3):952-956.

13. Preethi BP, Monika K, Maitreyee DS, Rashmi K. A hospital-based study of Hereditary Hemolytic Anaemias in Davanagere district of Karnataka, India. Bang J Med Sci. 2010;9(3):154-160.
14. Kaddah N, Salama K, Kaddah AM, Attia R. Epidemiological study among thalassemia intermedia pediatric patients. Med J Cairo Univ. 2010;78(2).

15. Cappellini MD, Cohen A, Porter J, Taher A, Viprakasit V, editors. Guidelines for the Management of Transfusion Dependent Thalassaemia (TDT) Nicosia (CY): Thalassaemia International Federation; 2014.

16. Chattopadhyay $\mathrm{K}$, Biswas $\mathrm{R}$, Bhattacherjee $\mathrm{S}$, Bandyopadhyay R. An epidemiological study on the clinic-hematological profile of patients with congenital hemolytic anemia in a tertiary care hospital of Kolkata. Indian J Prev Soc Med 2012;43:372-377.

17. Hashemi AS, Ghilian R, Golestan M, Akhavan Ghalibaf M, Zare Z, Dehghani MA. The study of growth in thalassemic patients and its correlation with serum ferritin level. Iranian J Pediatr Hematol Oncol. 2011; 1(4):147-151.

18. Samarakoon PS, Wijesuriya AP. A clinical audit of thalassaemia management at the Lady Ridgeway Hospital for Children, Colombo. Sri Lanka J Child Health.2011;40(2):48-53.doi: 10.4038/sljch.v40i2. 3090

19. Talsania S, Talsania N, Nayak H. A cross sectional study of thalassemia in Ahmedabad city, Gujarat (Hospital based). Healthline. 2011;2(1):48-51.

20. Mallik S, Chatterjee C, Mandal PK, Sardar JC, Ghosh P, Manna N. Expenditure to treat thalassaemia: an experience at a tertiary care hospital in India. Iran $\mathbf{J}$ Public Health. 2010;39(1):78-84. Epub 2010 Mar 31.

21. Cazzola M, Borgna-Pignatti C, Locatelli F, Ponchio L, Beguin Y, De Stefano P. A moderate transfusion regimen may reduce iron loading in beta-thalassemia major without producing excessive expansion of erythropoiesis. Transfus. 1997;37(2):135-140. doi: 10. 1046 /j. 1537-2995.1997.37297203514.x

\section{How to cite this article?}

Singh M, Dayal R, Kumar N, Singh S.P, Gupta L.K, Nayak M, Sharma R.K, Yadav A. Clinico-epidemiological profile of thalassemia patients in a tertiary care center. Int J Pediatr Res.2019;6(09):484-488.doi:10.17511/ijpr.2019.i09.08 